\title{
ENTERPRISE ARCHITECTURE PLANNING SISTEM INFORMASI USAHA KEPARIWISATAAN BERBASIS WEB
}

\author{
Rengga Herdiansyah \\ Fakultas Teknik, Universitas Pamulang \\ Email : the.herdiansyah@gmail.com
}

\begin{abstract}
ABSTRAK
Kemajuan teknologi informasi telah mempengaruhi berbagai bidang kehidupan, tidak terkecuali bidang bisnis pariwisata. Salah satunya adalah digunakannya teknologi internet sebagai media informasi. Tujuan dari penelitian ini adalah memberikan masukan kepada pelaku bisnis tour and travel akan manfaat pengembangan arsitektur bisnis dalam usaha kepariwisataan agar perusahaan dapat berperan serta memajukan pembangunan nasional khususnya dalam usaha kepariwisataan. Enterprise arcitecture planning menurut Spewak ini pemodelan sistemnya menggunakan Unified Modeling Language (UML) dan menggunakan software bahasa pemrograman PHP dan menggunakan database MySQL untuk penanganan database. Hasil dari program perancangan ini adalah berupa aplikasi berbasis web yang menyediakan informasi mengenai destinasi wisata, rute perjalanan wisata yang dapat ditempuh, serta fasilitas transportasi dan akomodasi yang tersedia. Diharapkan aplikasi ini dapat menjadi salah satu website kepariwisataan yang dapat dimanfaatkan juga oleh pemandu wisata. Penyediaan informasi kepariwisataan berbasis web selain akan memudahkan wisatawan dalam mengenal dan merencanakan perjalanan wisata, juga menunjang pengembangan database sektor kepariwisataan di Indonesia. Diharapkan wisatawan dapat memanfaatkan aplikasi Maps API juga Global Position System untuk memperoleh informasi kepariwisataan yang dibutuhkan.
\end{abstract}

Kata kunci: perancangan, enterprise architecture planning spewak, tour and travel, pariwisata, informasi.

\section{PENDAHULUAN}

Seiring dengan perkembangan teknologi yang semakin pesat, tidak dapat dipungkiri bahwa semakin banyak perusahaan kecil sampai perusahaan besar, lembaga pemerintahan maupun swasta yang telah memanfaatkan sistem informasi berbasis komputer demi meningkatkan kinerja perusahaannya, termasuk lembaga atau instansi yang bergerak dalam bidang kepariwisataan.

Prospek yang sangat strategis pada sektor pariwisata tentu menjadi peluang yang sangat berarti bagi Indonesia sebagai suatu negara yang memiliki kekayaan alam dan budaya yang sangat besar, yang membentang dan tersebar di lebih dari 17.000 pulau. Saat ini Negara Indonesia memiliki 50 destinasi pariwisata nasional (DPN), 222 kawasan pengembangan pariwisata nasional (KPPN) dan 88 kawasan strategis pariwisata nasional (KSPN).

Gambaran prospek strategis pariwisata sebagai pilar pembangunan nasional antara lain dapat ditunjukan dari angka kunjungan wisatawan baik nusantara maupun manca negara dalam beberapa tahun terakhir yang terus menunjukan peningkatan. Sektor pariwisata juga melibatkan jutaan tenaga kerja baik di bidang perhotelan, makanan, transportasi, pemandu wisata, maupun industri kerajinan.
Seperti yang dikutip oleh (Antariksa, 2012), W.R. McIntosh mengatakan ada beberapa hal yang menjadi motivasi yang mendorong seseorang untuk melakukan perjalanan diantaranya Pleasure (bersenang-senang), Relaxation, rest and recreation (beristirahat untuk menghapus stress), Health (kesehatan), Participation in sports (olahraga yang bersifat rekreasi), Curiousity and culture (rasa ingin tahu dan motivasi yang berkaitan dengan kebudayaan), Ethnic and family (kesamaan etnik dan kunjungan kepada keluarga), Spiritual and Religious (alasan yang bersifat spiritual dan keagamaan), Status and prestige (menunjukan status dan gengsi), Professional or business (melakukan aktivitas yang berkaitan dengan profesi/pekerjaan". Dengan melihat banyaknya motivasi wisatawan, destinasi pariwisata nasional, kawasan pengembangan pariwisata nasional dan kawasan strategis pariwisata nasional yang dimiliki Indonesia, memberikan begitu banyak peluang dan tantangan kepada masyarakat untuk dapat berperan serta dalam membantu pembangunan kepariwisataan guna mendorong pemerataan kesempatan berusaha dan memperoleh manfaat dari kepariwisataan. 


\section{ZACHMAN FRAMEWORK DAN ENTERPRISE PLANNING \\ Zachman Framework}

Kerangka kerja dapat diartikan sebagai sejumlah pemikiran, konsep, ide atau asumsi yang digunakan untuk mengorganisasikan proses pemikiran tentang sesuatu atau situasi. Kerangka kerja ini juga dapat dianggap sebagai dasar berpikir untuk mengelompokkan dan mengorganisasikan representasi sebuah perusahaan yang penting bagi manajemen perusahaan dan pengembangan sistem selanjutnya (Zachman, 2003).

Zachman Framework, dikeluarkan oleh Zachman Institut for Framework Advancement (ZIFA), John Zachman mempublikasikan pendekatan yang berbeda untuk system development. Zachman Framework menggambarkan arsitektur organisasi secara umum dan menguraikannya sebagai enterprise system yang kompleks (Spewak \& Tiemann, 2006), dalam dunia bisnis, organisasi akan dituntut untuk melakukan manajemen terhadap perubahan yang bertujuan dengan keunggulan bersaing antara organisasi dengan para pesaingnya.

Kerangka kerja Zachman bukan suatu metodologi untuk mengembangkan enterprise architecture, akan tetapi kerangka kerja Zachman merupakan kerangka kerja untuk mengkategorikan artifak enterprise architecture. Kerangka kerja Zachman dapat dimanfaatkan untuk menentukan apakah suatu metodologi meliputi semua aspek dalam enterprise architecture atau aspek apa saja yang dicakup oleh metodologi, kerangka kerja Zachman untuk enterprise architecture terdiri dari 6 (enam) kolom dan 6 (enam) baris (Zachman, 2003).

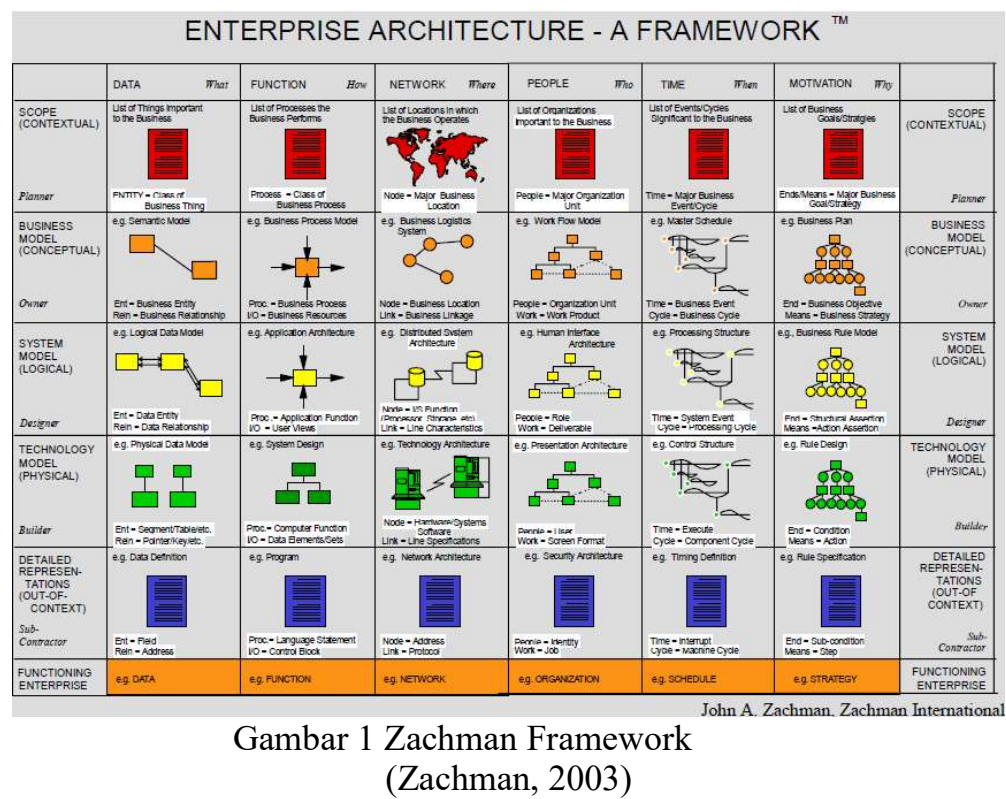

Baris-baris pada Kerangka kerja mewakili tingkat abstraksi yang digunakan untuk melakukan analisis sistem (Suryana, 2012). Setiap baris pada kerangka kerja Zachman mewakili perspektif yang berbeda dan unik yaitu:

1. Perspektif Perencana (Ballpark View), yaitu menetapkan konteks, latar belakang dan tujuan enterprise.

2. Perspektif Pemilik (Owner's View), yaitu menetapkan model-model konseptual dari enterprise.

3. Perspektif Perancang (Designer's View), yaitu menetapkan model-model sistem informasi sekaligus menjembatani hal-hal yang diinginkan pemilik dan hal-hal yang dapat direalisasikan secara teknis dan fisik.

4. Perspektif Pembangun (Builder's View), yaitu menetapkan rancangan teknis dan fisik yang digunakan dalam mengawasi implementasi teknis dan fisik.

5. Perspektif Subkontraktor (Subcontractor), yaitu menetapkan peran dan rujukan bagi pihak yang bertanggung jawab untuk melakukan pembangunan secara teknis dan fisik serta mengadakan komponenkomponen yang diperlukan.

6. Perspektif Fungsi Sistem, yaitu merepresentasikan perspektif pengguna dan wujud nyata hasil implementasi. 
Sedangkan aktivitas utama pengelolaan data skala enterprise yang terdapat pada kolom-kolom kerangka kerja (Zachman, 2003), adalah:

1) What (data): menggambarkan kesatuan yang dianggap penting dalam bisnis, kesatuan tersebut adalah hal-hal yang informasinya perlu dipelihara.

2) How (Functions): mendefinisikan fungsi atau aktivitas. Input dan output juga dipertimbangkan di kolom ini.

3) Where (Network): menunjukkan lokasi geografis dan hubungan antara aktivitas dalam organisasi, meliputi lokasi geografis bisnis yang utama.

4) Who (People): mewakili manusia dalam organisasi dan metrik untuk mengukur kemampuan dan kinerjanya. Kolom ini juga berhubungan dengan antar muka pengguna dan hubungan antar manusia dan pekerjaan yang menjadi tanggung jawabnya.
5) When (Time): mewakili waktu atau kegiatan yang menunjukkan kriteria kinerja. Kolom ini berguna untuk mendesain jadwal dan memproses arsitektur.

6) Why (Motivation): menjelaskan motivasi dari organisasi dan pekerjaannya. Disini terlihat tujuan, sasaran, rencana bisnis, arsitektur pengetahuan, alasan pikiran, dan pengambilan putusan dalam organisasi.

\section{Enterprise Architecture Planning}

Enterprise Arcitecture Planning adalah suatu metode pendekatan perencanaan kualitas data yang berorientasi pada kebutuhan bisnis serta bagaimana cara implementasi dari arsitektu tersebut dilakukan sedemikian rupa dalam usaha untuk mendukung perputaran roda bisnis dan pencapaian misi sistem dan organisasi (Spewak S. H., 1992). Dimana komponen dari metodologi EAP menurut Spewak menggunakan dasar 2 baris atas dari kerangka kerja John Zachman tentang scope (planner) and business model (owner).

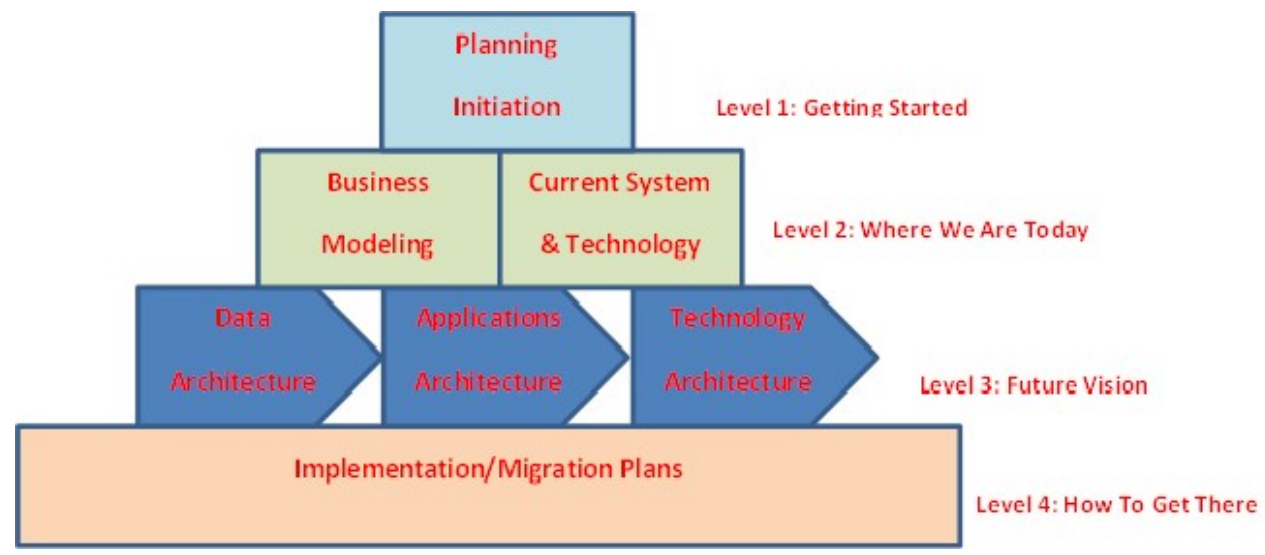

Gambar 2 Tahapan Enterprise Architecture Planning

(Spewak S. H., 1992)

Setiap lapisan mencerminkan tahapantahapan pengembangan (kegiatan yang dilakukan). Setiap komponen atau fase Enterprise Architecture Planning (EAP) menjelaskan bagaimana mendefinisikan arsitektur dan perencanaan. Komponen-komponen tersebut terbentuk sebagai Layer, dimana setiap Layer merepresentasikan fokus tugas yang berbeda, yaitu:

1) Layer 1 - Getting Started. Inisiasi Perencanaan (Planning Initiation): memulai Enterprise Architecture Planning (EAP) pada jalur yang benar, termasuk menentukan metodologi yang digunakan, siapa yang harus dilibatkan dan toolset apa yang digunakan.

2) Layer 2 - Where We Are Today. a. Pemodelan Bisnis (Business Modeling): menyusun knowledge base mengenai bisnis dan informasi yang digunakan untuk melaksanakan bisnis.

b. Sistem dan Teknologi Saat Ini (Current Systems and Technology): mendefinisikan sistem aplikasi apa yang terdapat saat ini dan platform teknologi yang mendukung.

3) Layer 3 - Future Vision.

a. Arsitektur Data (Data architecture): mendefinisikan data yang diperlukan untuk mendukung bisnis.

b. Arsitektur Aplikasi (Application Architecture): mendefinisikan aplikasi yang diperlukan untuk mengelola data dan mendukung fungsi-fungsi bisnis. 
c. Arsitektur Teknologi (Technology Architecture): mendefinisikan platform teknologi yang diperlukan untuk menyediakan lingkungan bagi aplikasi yang mengelola data dan mendukung fungsi bisnis.

4) Layer 4 - How We Get There.

Rencana Implementasi/Migrasi

(Implementation/Migration Plans): mendefnisikan urutan langkah untuk mengimplementasikan aplikasi, jadwal implementasi, analisis manfaat atau biaya, dan mengajukan jalur yang jelas untuk melakukan migrasi dari where we aretoday ke where we want to be.

\section{PEMBAHASAN}

Inisiasi Perencanaan (Planning Initiation)

Posisi bisnis PT. Kirani Mercury Abadi (Mercury Tour \& Travel), berdasarkan penggunaan framework Product Portofolio (Boston) Matrix, maka PT. Kirani Mercury Abadi saat ini disimpulan berada pada posisi Wildcat / Problem Child. Kesimpulan penempatan posisi tersebut berdasarkan pada karakteristik dari kuadran ini yaitu market growth yang tinggi dengan market share yang rendah atau sedikit, tetapi mempunyai peluang yang cukup besar untuk bergerak kearah kuadran Star jika situasi dapat terus ditingkatkan.
(a) Market Growth
(b)Cash Use
STAR
WILDCAT
OR
LOW
CASH COW
HIGH
PROBLEM CHILD
Gambar 3 Posisi Relatif PT. Kirani Mercury Abadi

Pemodelan Proses Bisnis (Business Modeling)

Identifikasi terhadap area fungsional utama

dari PT. Kirani Mercury Abadi digunakan value

chain. Area fungsional dari PT. Kirani Mercury
Abadi yang teridentifikasi kemudian dipresentasikan dengan menggunakan value chain seperti pada gambar 4 .

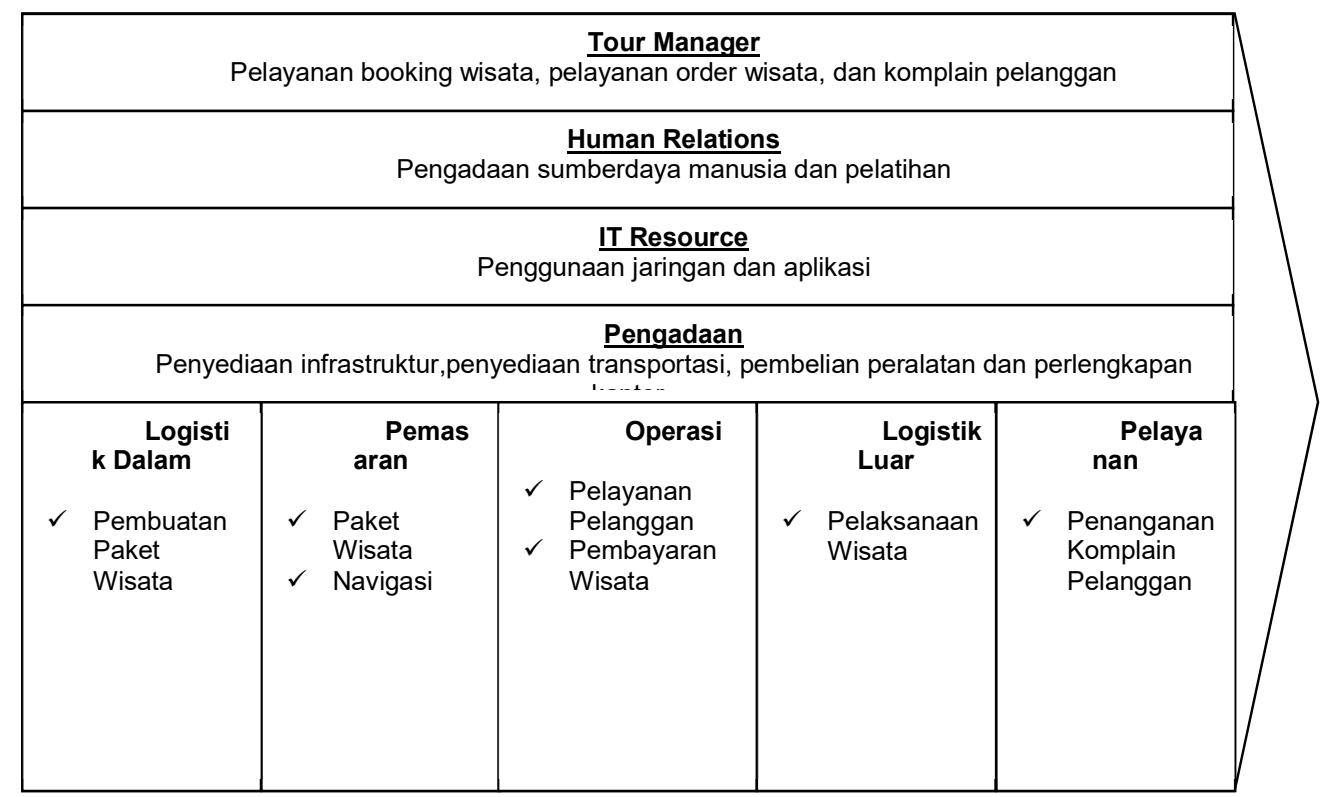

Gambar 4 Value Chain PT. Kirani Mercury Abadi

Tahap mendefinisikan tentang bisnis yang dilakukan oleh PT. Kirani Mercury Abadi Bandung khususnya yang berkaitan dengan bidang kepariwisataan dengan menggunakan value chain analysis dan usecase diagram untuk proses bisnis 
utamanya yang kemudian digambarkan dengan menggunakan Business Usecase.

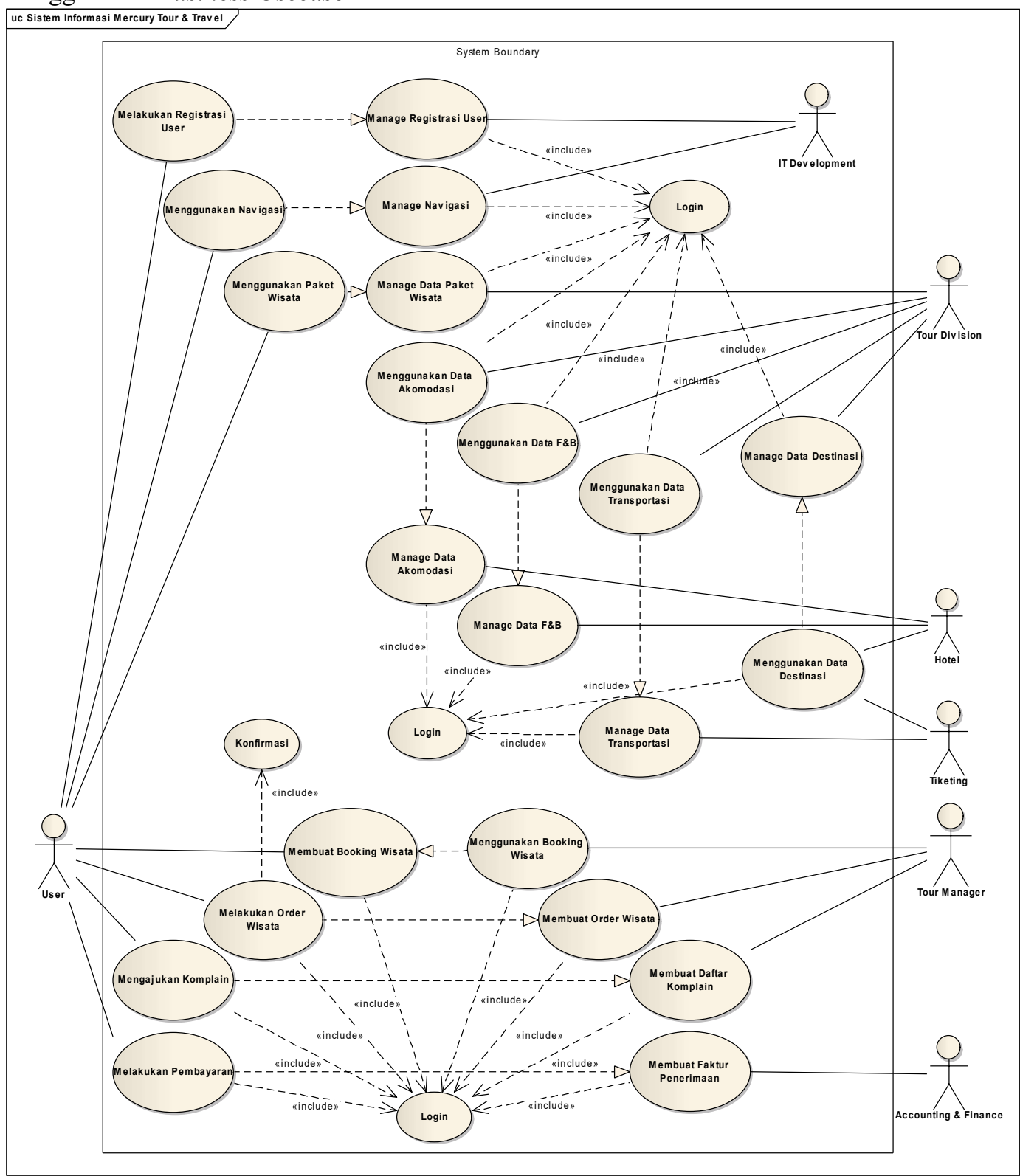

Gambar 5 Usecase Diagram Sistem Informasi Manajemen PT. Kirani Mercury Abadi

Sistem dan Teknologi Saat Ini (Existing System and Technology)

Pada saat melakukan observasi lapangan, sumber daya teknologi yang dimiliki oleh PT. Kirani Mercury Abadi di Kantor Cabang Bandung seperti yang terdapat pada Tabel 1. Laptop digunakan oleh Direktur dan Kepala Cabang, PC digunakan oleh IT Development dan Accounting \& Finance dan 1 PC terakhir digunakan oleh Tour Division, bagian Hotel, serta bagian Tiketing.

Tabel 1 Sumber Daya Teknologi Saat Ini Jenis Teknologi Unit Laptop 2

Personal Computer 3 Printer 


\section{Arsitektur Data (Data Architecture)}

Pada arsitektur data dikelompokan menjadi 4 proses utama, diantaranya Sistem Pembuatan Paket Wisata, Sistem Pelayanan Pelanggan dan Pembayaran Wisata, Sistem Persiapan Pelaksanaan Wisata, Sistem Pelayanan Komplain dan Pembayaran.

Seperti yang diilustrasikan dalam gambar 6, pada kelompok sistem pembuatan paket wisata terdapat 10 tabel yang dibutuhkan dalam membuat sebuah data paket wisata, diantaranya:
1. Tabel Paket Wisata

2. Tabel Paket Wisata Detail

3. Tabel Destinasi

4. Tabel Destinasi Detail

5. Tabel Akomodasi

6. Tabel Akomodasi Detail

7. Tabel FB

8. Tabel FB Detail

9. Tabel Transportasi

10. Tabel Transportasi Detail

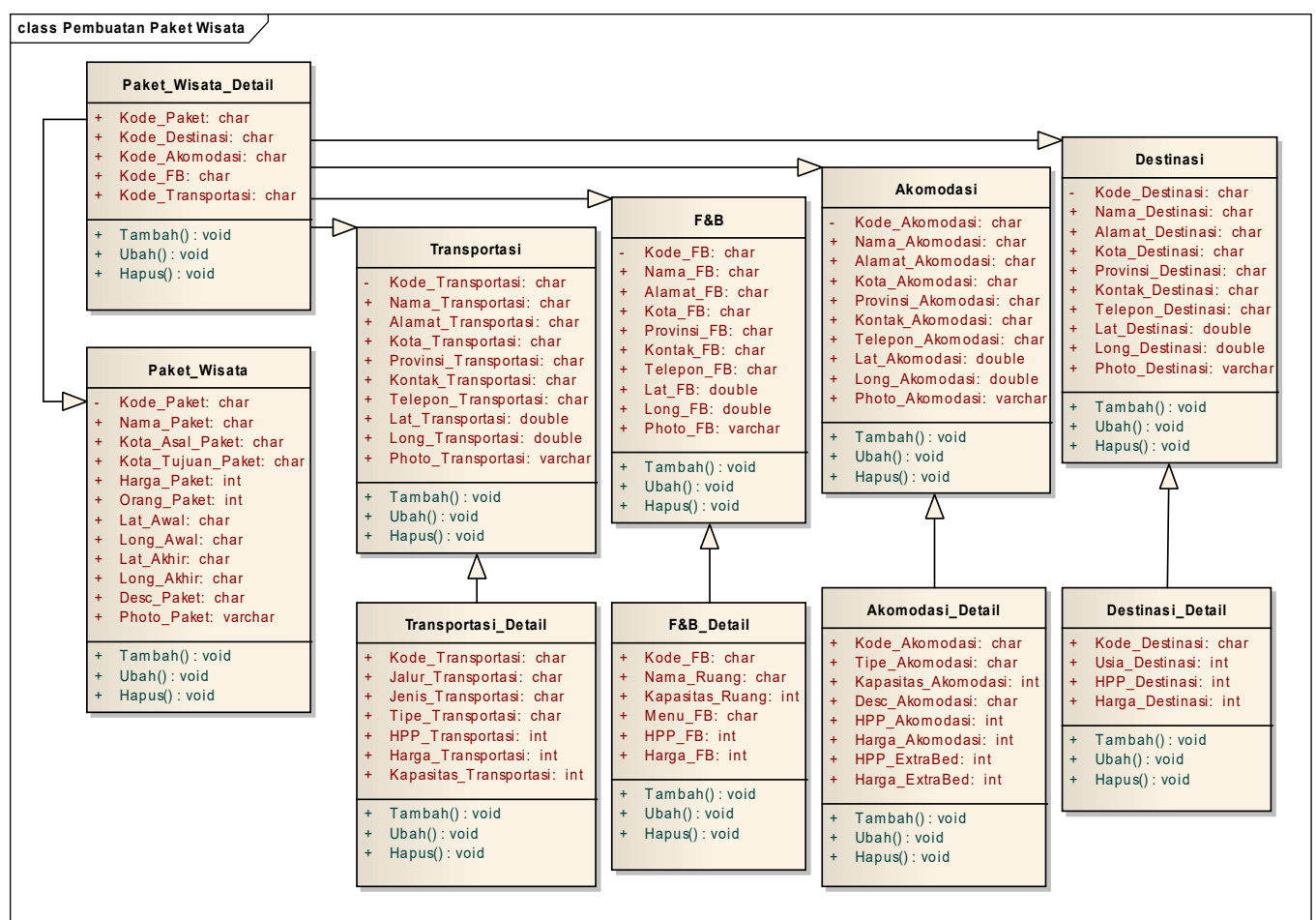

Gambar 6 Class Diagram Pembuatan Paket Wisata PT. Kirani Mercury Abadi

Pada kelompok sistem penjualan paket wisata seperti yang digambarkan pada gambar 7 , terdapat 4 tabel yang dibutuhkan, diantaranya:

1. Tabel Pegawai
2. Tabel Pelanggan

3. Tabel Order Wisata

4. Tabel Faktur Wisata 


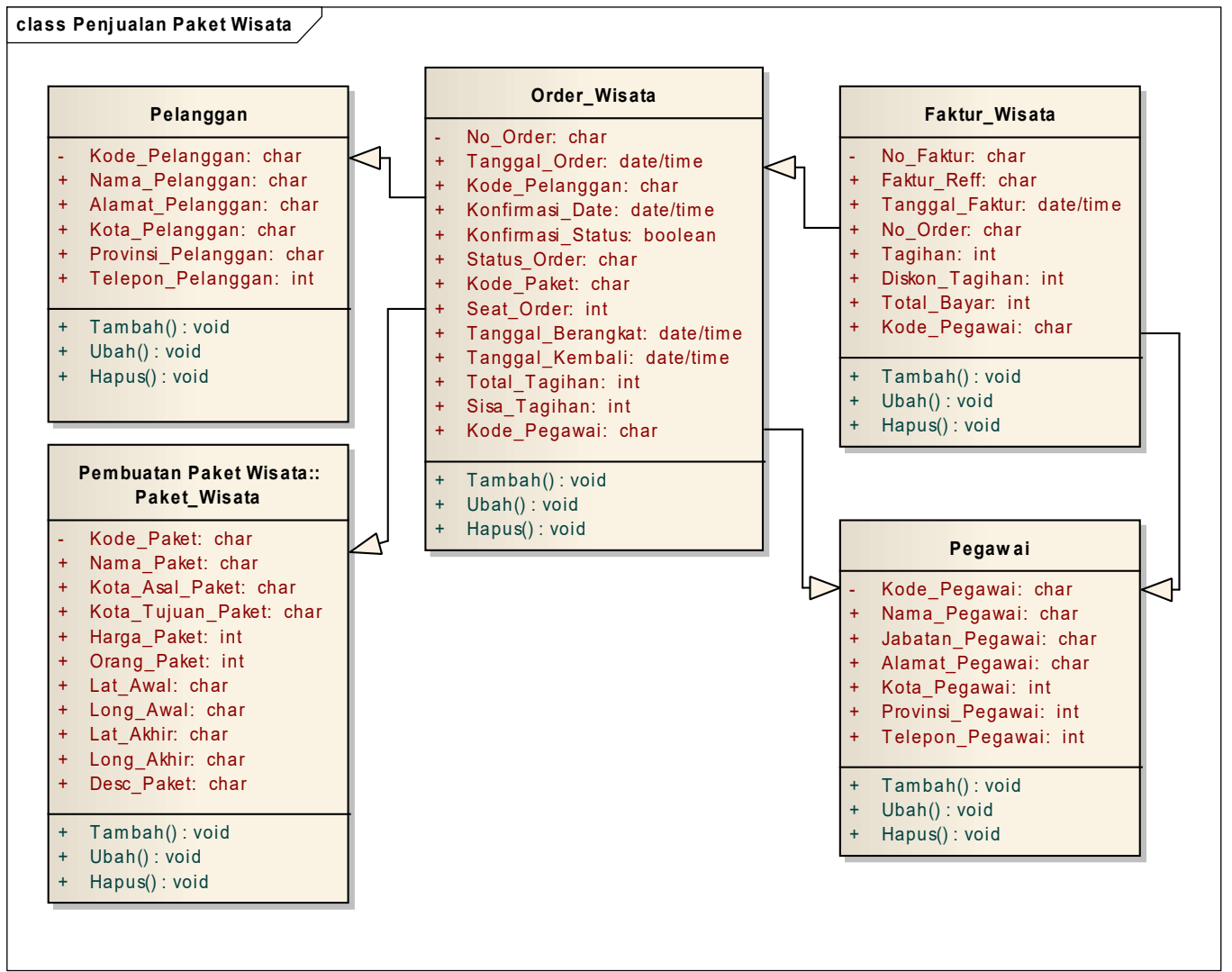

Gambar 7 Class Diagram Penjualan Paket Wisata PT. Kirana Mecury Abadi

Pada kelompok sistem persiapan pelaksanaan wisata seperti yang digambarkan pada gambar 8 , terdapat 5 tabel yang dibutuhkan, diantaranya:

1. Tabel Persiapan Wisata
2. Tabel Persiapan Destinasi

3. Tabel Persiapan Akomodasi

4. Tabel Persiapan FB

5. Tabel Persiapan Transportasi

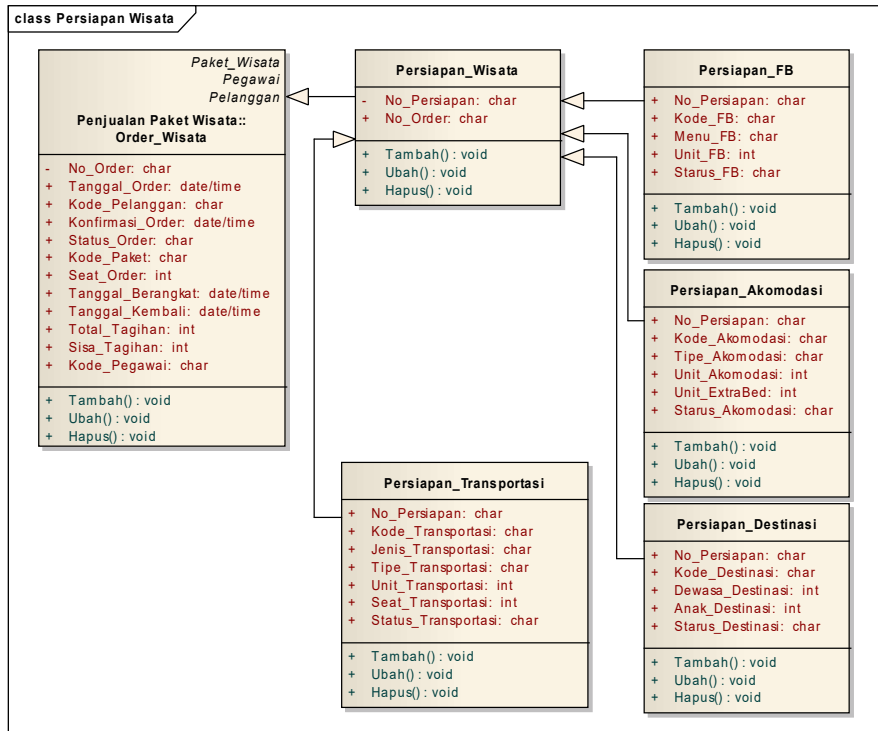

Gambar 8 Class Diagram Persiapan Paket Wisata PT. Kirani Mercury Abadi 
Pada kelompok sistem penjualan paket wisata seperti yang digambarkan pada gambar 9 , terdapat 3 tabel yang dibutuhkan, diantaranya:
1. Tabel Komplain Pelanggan

2. Tabel Pengeluaran

3. Tabel Laporan Keuangan

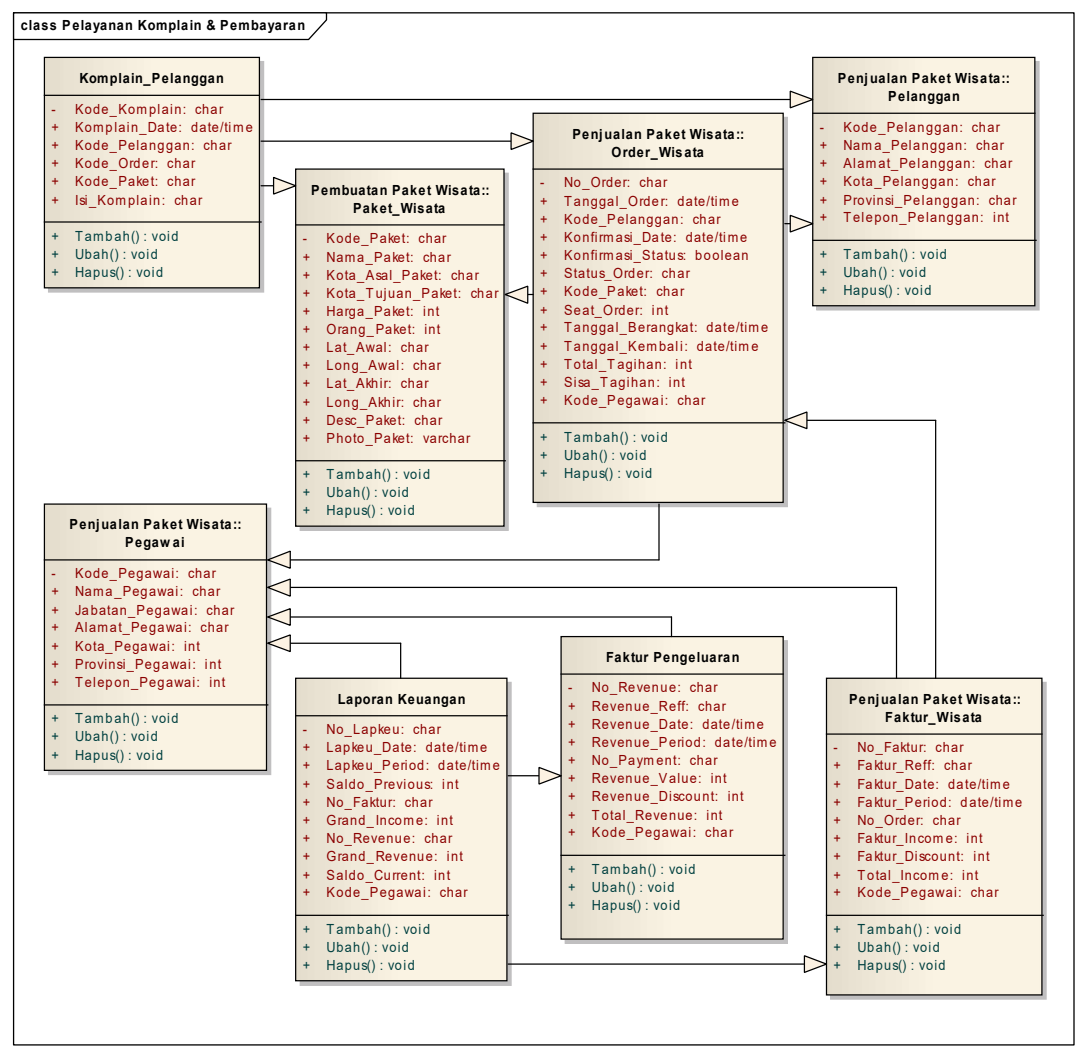

Gambar 9 Class Diagram Pelayanan Komplain dan Pembayaran PT. Kirani Mercury Abadi

\section{Arsitektur Aplikasi (Application Architecture)}

Di dalam arsitektur aplikasi terdapat 4

(empat) kelompok sistem aplikasi seperti yang dijabarkan dalam tabel 2.

Tabel 2 Kelompok Sistem Aplikasi

\begin{tabular}{|c|c|c|}
\hline No. & Kelompok Sistem Aplikasi & Aplikasi \\
\hline \multirow[t]{5}{*}{1.} & \multirow[t]{5}{*}{ Sistem Pembuatan Paket Wisata } & Pengumpulan Data Destinasi \\
\hline & & Pengumpulan Data Akomodasi \\
\hline & & Pengumpulan Data F\&B \\
\hline & & Pengumpulan Data Transportasi \\
\hline & & Pembuatan Paket Wisata \\
\hline \multirow[t]{7}{*}{2.} & \multirow[t]{7}{*}{ Sistem Pelayanan Pelanggan } & Pengelolaan User \\
\hline & & Pengajuan Order Wisata \\
\hline & & Pemberian Detail Paket Wisata dan \\
\hline & & Batas Konfirmasi \\
\hline & & Persetujuan dan Konfirmasi Detail \\
\hline & & Paket Wisata \\
\hline & & Pengajuan Komplain Pelanggan \\
\hline \multirow[t]{3}{*}{3.} & \multirow[t]{3}{*}{ Sistem Pembayaran } & Pembayaran Paket Wisata \\
\hline & & Pembuatan Laporan Pengeluaran \\
\hline & & Pembuatan Laporan Keuangan \\
\hline \multirow[t]{2}{*}{4.} & \multirow{2}{*}{$\begin{array}{l}\text { Persiapan Persiapan } \\
\text { Pelaksanaan Wisata }\end{array}$} & Persiapan Wisata \\
\hline & & Persiapan Destinasi \\
\hline
\end{tabular}


Persiapan Transportasi

Persiapan Akomodasi

Persiapan F\&B

\section{Arsitektur Teknologi (Technology Architecture)}

Seperti digambarkan pada gambar 10 , calon wisatawan, wisatawan, dan petugas yang berada dilapangan dapat memanfaatkan fitur atau fasilitas yang terdapat pada website Mercury Tour \& Travel. Mulai dari fitur navigasi sebagai panduan dalam melakukan wisata atau bahkan melihat-lihat tempat apa yang tersedia disekitarnya serta calon wisatawan juga bisa mendapatkan pelayanan melalui perangkat yang mereka miliki seperti personal computer (PC), laptop, dan telepon seluler yang dapat melakukan akses internet.

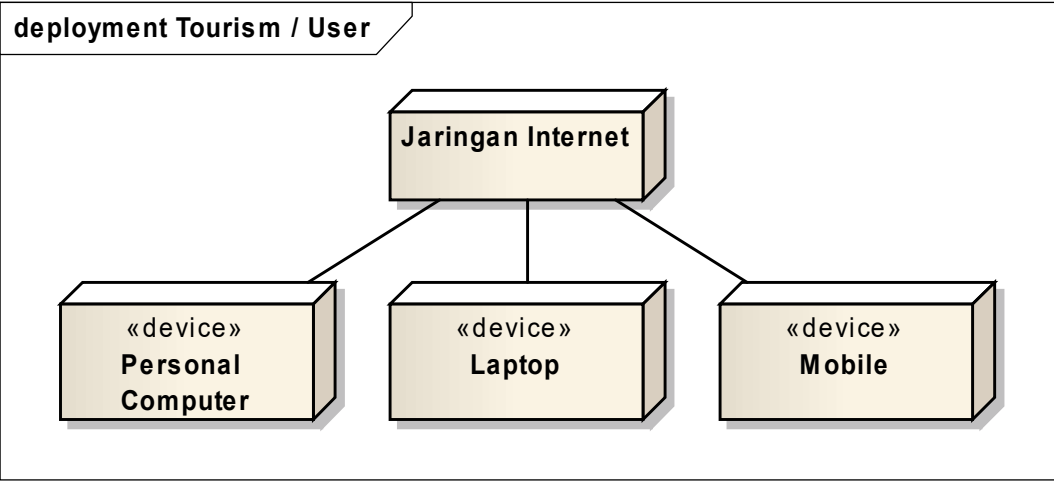

Gambar 10 Deployment Diagram Pengguna PT. Kirani Mercury Abadi

Jaringan atau akses internet langsung diakses oleh komputer bagian IT Development, karena komputer bagian IT development berfungsi sebagai komputer server untuk jaringan LAN didalam kantor pusat atau kantor cabang itu sendiri seperti yang diilustrasikan pada gambar 11.

Akses internet yang diterima bagian IT development kemudian diteruskan ke komputer kepala cabang, accounting \& finance, hotel, tiketing, tour manager, domestic division, inbound division, outbound division dengan menggunakan HUB atau yang biasa dikenal dengan switch. Juga tidak lupa disediaan sebuah printer untuk mencetak laporan-laporan dan lainnya.

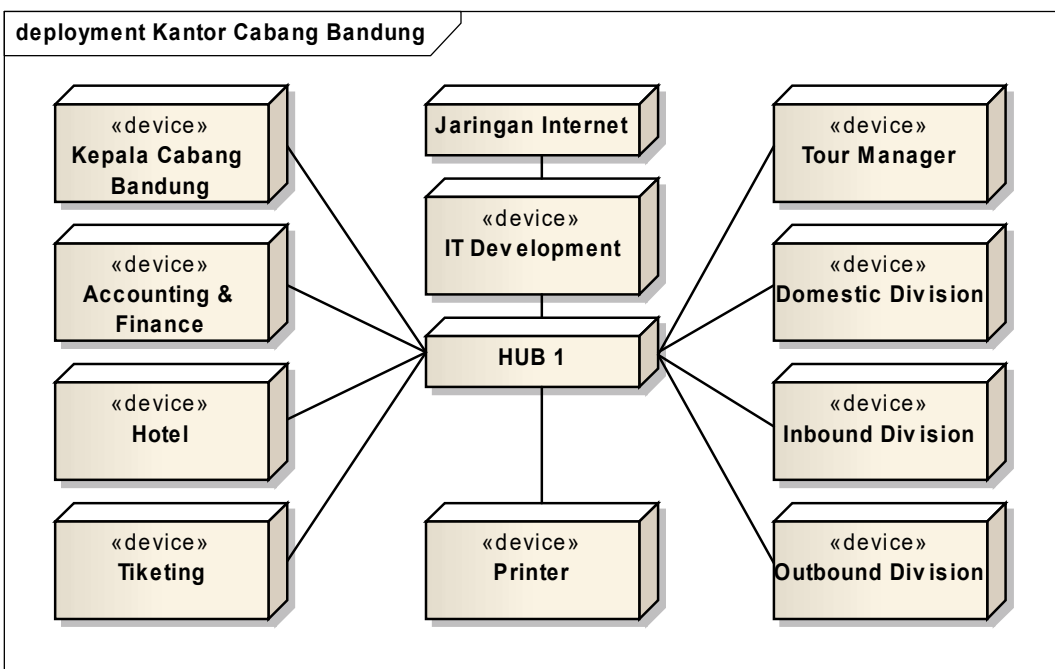

Gambar 11 Deployment Diagram Kantor Cabang Bandung PT. Kirani Mercury Abadi

Implementasi (Implementation) 
Dalam melakukan implementasi, akan digambarkan tahapan implementasi dengan menggunakan roadmap implementation seperti pada gambar 12. Berikut tahapan yang akan dilakukan dalam implementasi:

1. Pengadaan dan Pemasangan Infrastruktur
2. Sistem Pembuatan Paket Wisata

3. Sistem Pelayanan Pelanggan

4. Sistem Pembayaran Wisata

5. Sistem Persiapan Wisata

6. Pelatihan Sumber Daya Manusia

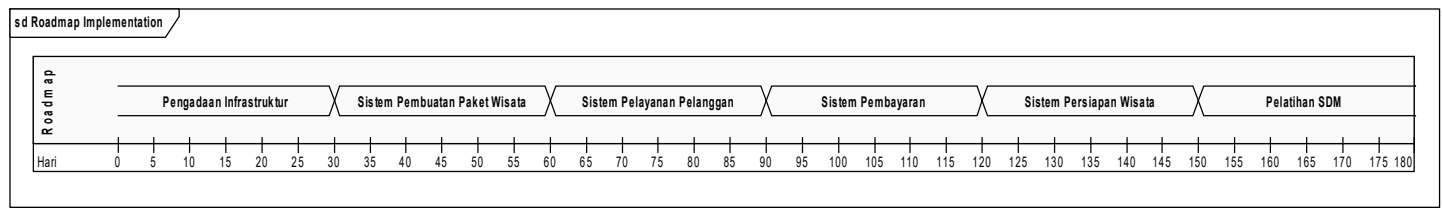

Gambar 12 Roadmap Implementation PT. Kirani Mercury Abadi 


\section{KESIMPULAN}

Berdasarkan uraian yang telah disampaikan pada bahasan sebelumnya, berikut adalah hasil kesimpulan yang didapat:

1) Pelaku usaha perjalanan wisata akan dapat memanfaatkan pengembangan enterprise architecture dalam usahanya agar dapat memberikan kepuasan kepada para pelanggannya dan secara tidak langsung juga berperan serta memajukan pembangunan nasional bidang kepariwisataan.

2) Pengembangan enterprise architecture usaha kepariwisataan berbasis web application akan memberikan keuntungan besar bagi perusahaan karena dapat dilakukan bertahap sesuai kebutuhan dan kemampuan namun sudah ada perencanaan untuk pengembangan selanjutnya.

3) Memberikan masukan kepada pelaku bisnis tour dan travel akan manfaat pengembangan enterprise dalam usaha kepariwisataan untuk berperan serta memajukan pembangunan nasional khususnya usaha kepariwisataan.

4) Merencanakan pengembangan enterprise usaha kepariwisataan berbasis web application sesuai dengan tahapan-tahapan yang harus dilakukan, agar pengembangan berjalan dengan konsep yang jelas dan terarah.

5) Merencanakan penyediaan informasi mengenai destinasi wisata, rute perjalanan yang dapat ditempuh, fasilitas akomodasi yang tersedia serta diharapkan wisatawan dapat memanfaatkan aplikasi pemandu wisata meskipun tidak mengambil paket wisata dengan memanfaatkan fitur Google Maps API juga Global Position System bila memungkinkan.

Berdasarkan uraian yang telah disampaikan pada bahasan sebelumnya, berikut adalah saran yang dapat disampaikan dalam pengembangan enterprise architecture planning sistem informasi usaha kepariwisataan:

1) Perlunya memasukan unsur manajemen resiko dalam rencana implementasi EAP. Rencana implementasi tak lain merupakan suatu rencana proyek berskala besar untuk implementasikan cetak biru yang telah dihasilkan. Untuk itu perlu dimasukan unsur untuk meminimalkan resiko-resiko yang mungkin terjadi demi keberhasilan implementasi EAP.

2) Untuk aplikasi berbasis website, sebuah keamanan data perusahaan perlu diperhitungkan mengingat data dari sebuah perusahaan merupakan sesuatu hal yang penting untuk dijaga kerahasiaannya.

3) Dalam pemodelan bisnis yang terletak pada lapisan 2 EAP harus sering dikomunikasikan kepada pemilik (owner). Hal ini dilakukan untuk mendapatkan perubahan yang perlu dilakukan dalam model bisnis. Perubahan model bisnis yang berkaitan dengan peluang peningkatan atau perbaikan dan lainnya.

4) Dalam proses pembayaran wisata yang dilakukan calon pelanggan atau wisatawan, dirasakan perlu adanya fasilitas untuk pembayaran secara online yang membutuhkan adanya kerjasama dengan lembaga keuangan atau bank tertentu sehingga proses pembayaran tidak hanya dapat dilakukan dengan cara transfer melalui atm.

\section{DAFTAR PUSTAKA}

Alamsyah, Z. (2003). Manajemen Sistem Informasi. Jakarta: PT Gramedia Pustaka Utama.

Antariksa, B. (2012). Peluang dan Tantangan Pengembangan Kepariwisataan di Indonesia. Retrieved 3 Oktober, 2013, from Departemen Budaya dan Pariwisata: http://www.budpar.go.id/userfiles/file/Art_172-Konsep\%20Ekonomi\%20Kreatif.pdf

Gunawan, M., \& Ortis, O. (2012). Rencana Strategis Pariwisata Berkelanjutan dan Green Jobs untuk Indonesia. Jakarta: Kementerian Pariwisata dan Ekonomi Kreatif Republik Indonesia danInternational Labour Organization.

Hanif Al Fatta. (2007). Analisis \& Perancangan Sistem Informasi. Yogyakarta: C.V Andi Offset.

Hermawan, J. (2004). UML dan VB.NET. Yogyakarta: ANDI OFFSET.

Irawan, B. (2005). Jaringan Komputer. Yogyakarta: Graha Ilmu.

Jogiyanto. (2001). Sistem Teknologi Informasi. Jogjakarta: Andi Publisher.

Jogiyanto, H. (2009). Sistem Teknologi Informasi Edisi III. Yogyakarta: Andi.

Melwin. (2005). Pengantar Jaringan Komputer. Yogyakarta: Andi Publisher.

Peranginangin. (2006). Aplikasi Web dengan PHP dan MySQL . Yogyakarta: Andi Publisher.

PERMEN. (2004). Peraturan Menteri Kebudayaan Dan Pariwisata No: KM.67 / UM.001 /MKP/ 2004 Tentang Pedoman Umum Pengembangan Pariwisata Di Pulau-Pulau Kecil. In M. K. 
Pariwisata, MENBUDPAR (pp. 1-27). Indonesia: DEPDIKBUD.

Rosa \& Shalahuddin. (2014). REKAYASA PERANGKAT LUNAK. BANDUNG: INFORMATIKA.

Sanders, Chandima, \& Williams. (2007). Object Oriented Programing Technique. United States of America: O'Reilly Media.

Siswanto, N. a. (2010). Satelit TIK: Teknologi Informasi dan Komunikasi. Jakarta: Pusat Perbukuan, Kementrian Pendidikan Nasional.

Spewak, S. H. (1992). Enterprise Architecture Planning (Developing a Blueprint for Data Appliication and Technology). Jhon Wiley \& Sons, Inc.

Spewak, S., \& Tiemann, M. (2006). Updating The Enterprise Architecture Planning. Journal of Enterprise Architecture Model, 12-19.

Suryana, T. (2012). Perancangan Arsitektur Teknologi Informasi Dengan Pendekatan Enterprise Architecture Planning. Majalah Ilmiah UNIKOM, 223-236.

Sutarman. (2007). Membangun Aplikasi Web dengan PHP dan MySQL. Yogyakarta: Graha Ilmu.

Tabrani, M. (2014). IMPLEMENTASI SISTEM INFORMASI RESERVASI PENGINAPAN PADA ARGOWISATA GUNUNG MAS CISARUA BOGOR. Reservasi, Agrowisata, 38-49.

Turban. (2003). Introduction to Information Technology, 2nd Edition. USA: John Wiley \& Sons, Inc.

Welling, L., \& Thomson, L. (2001). PHP and MySQL Web Development. United States: Sams.

Yuliana, A., Aradea, \& Himawan, H. (Mei , 2010). Perancangan Arsitektur Informasi Untuk Mendukung Keberlangsungan Proses Bisnis Enterprise Wide. Seminar Nasional Informatika 2010 (semnasIF 2010).

Zachman, J. A. (2003). The Zachman Framework For Enterprise Architecture: Primer for Enterprise Engineering and Manufacturing. Zachman International.

Zalukhu, S. (2009). Ekowisata: Panduan Dasar Pelaksanaan. Nias: Dinas Pariwisata dan Kebudayaan Kabupaten Nias Selatan. 